\title{
ABORDAGEM CLÍNICA NO CONTEXTO COMUNITÁRIO: UMA PERSPECTIVA INTEGRADORA
}

\author{
Liana Fortunato Costa \\ Universidade de Brasília \\ Shyrlene Nunes Brandão \\ Universidade Católica de Brasília
}

\begin{abstract}
RESUMO: Esse texto busca circunscrever uma categoria de intervenção que é de natureza clínica, mas que ocorre em contexto social/comunitário. Os conceitos de clínica e de comunidade são brevemente discutidos, a fim de que o desenvolvimento dessa intervenção surja não da superposição ou transposição de abordagens, mas, sobretudo, que possibilite reformular e criar novas formas de atuação. Propomos definir uma prática que revela uma epistemologia, que se situa nessa observação clínica, mas que também é do contexto, do grupo, da família e da dimensão política, porque se passa nessa zona complementar de interação de pessoas que são sujeitos de emoção e afeto, mas seres sociais por excelência.

Palavras-chave: Psicologia Clínica; Psicologia Social Comunitária; Psicossociologia; comunidade; intervenção comunitária.
\end{abstract}

\section{CLINICAL APPROACH IN A COMMUNITARIAN CONTEXT: AN INTEGRATING PERSPECTIVE}

ABSTRACT:This paper focuses on a category of intervention which is of clinical nature, although it occurs in a social/community context. We briefly discuss the concepts of clinic and community, so that the development of such intervention may emerge not from the juxtaposition or transposition of approaches, but, above all, that it gives the possibility of reformulating and creating new courses of action. We propose the definition of a practice which reveals an epistemology, which is situated in clinical observation as well as belonging to a context, group, family and political dimension, because it takes place in the complementary zone of interaction among people who are subjects of emotion and affection, however, social beings per excellence. Key-words: clinical psychology, community social psychology, psychossociology, community, community intervention.

A complexidade dos objetos de estudos da psicologia levou a uma diversidade teórico-metodológica que visa explicar/compreender e intervir nos fenômenos estudados, em diferentes áreas de atuação dessa ciência. Não é possível pensarmos a Psicologia apenas a partir de uma abordagem, nem como sendo representada por uma área de atuação. No entanto, essa multiplicidade que poderia enriquecer, ao se fechar em suas compreensões, depaupera a capacidade do profissional de promoção do bem-estar dos indivíduos e da comunidade, um dos princípios fundamentais do exercício da profissão de Psicólogo (Conselho Federal de Psicologia, 1987). Diante dessa questão e do desafio da complexidade dos fenômenos abordados em Psicologia Comunitária, buscamos nesse texto circunscrever uma proposta de intervenção clínica, que ocorre em contexto de comunidade, e que considera o contexto social mais amplo, e suas influências sobre os sujeitos, os grupos e as famílias.

Essa discussão será traçada a partir das contribuições de cinco campos do conhecimento da Psico- logia e da Sociologia: Psicologia Clínica, Psicologia Social Comunitária, Psicologia Sócio-histórica, Psicossociologia e a Sociologia Clínica. Cada uma dessas áreas, algumas com diferentes fundamentações epistemológicas e não redutíveis umas às outras, tem contribuído para construir uma prática não proveniente da superposição ou transposição de modelos, mas, sobretudo, da tentativa de reformulação e elaboração de novas formas de atuação.

Esse texto está organizado em um primeiro momento, no qual serão discutidas algumas contribuições epistemológicas dessas áreas para a proposta de intervenção, e em seguida o desenvolvimento da proposta.

\section{CLÍNICA COMO ABORDAGEM}

Ao propormos o diálogo da Psicologia Social Comunitária com a Psicologia Clínica, tomamos o significado de clínica em nossa proposta, não como uma área, mas como uma abordagem, uma forma de olhar. Alguns teóricos da Psicossociologia e da Socio- 
logia Clínica, a nosso ver, definem de uma forma ampla essa compreensão de clínica ao voltarem à origem da palavra.

Barbier (1985) explica que a origem da palavra clínica provém do grego, kliné, que significa "procedimento de observação direta e minuciosa" (p. 45). Esse autor também aponta que a clínica inclui a exploração e compreensão dos significados presentes nas ações do sujeito, bem como dos grupos de sujeitos, buscando-se lhes apreender o sentido que leva a determinadas direções de relacionamentos, conflitos e decisões. Para Sévigny (2001) o sentido etimológico da palavra se refere à observação direta, junto ao leito do paciente. Essa compreensão tem norteado a proposta do autor de uma abordagem clínica nas ciências humanas, na qual o foco é a mudança, prevenção ou melhoria de uma determinada situação, no sentido de construção de novas respostas.

Na proposta apresentada nesse texto, o "leito" é a comunidade, as famílias, grupos e instituições que dela fazem parte. A complexidade presente nesse contexto exige que utilizemos diferentes contribuições teóricas, sem reduzi-las, mas reconhecendo os aspectos convergentes e divergentes presentes entre elas. Por um lado, atuamos numa perspectiva que Vasconcellos (2002) aponta como sistêmica, na medida em que reconhece o pensamento estruturado no tripé: subjetividade, complexidade e contexto. Esses três aspectos são bases da compreensão e das ações com os grupos e/ou indivíduos. Por outro lado também pautamos nossa leitura numa perspectiva de que as relações na comunidade estão permeadas por relações de poder, e que esse poder está intimamente vinculado ao pertencimento, a classe social e ao momento histórico (Saffioti, 1992).

\section{COMUNIDADE: CONTEXTO DE RELAÇÕES}

Conceituamos comunidade como dimensão espaço/temporal na qual os sujeitos são compreendidos com foco em suas relações, sendo constituídos por meio destas, em uma constante dialética entre individual e coletivo. A comunidade se expressa como espaço de construção de cidadania, no qual todas as falas são legítimas (Freitas, 2000; Guareschi, 2003). Esse conceito, que pode parecer utópico, é tomado nessa perspectiva para que marque o desafio de atuarmos focando as relações entre indivíduos, e entre estes e a sociedade, em uma busca de valorização das relações comunitárias que visem o bem comum (Ricci, 2003).

Nos últimos quinze anos temos trabalhado na sistematização de metodologias de intervenção clínica em contexto comunitário (Costa, 1998; Costa 1998 a; Costa, 1998/1999; Costa, 1999; Costa, 2003; Brandão, 2001; Brandão e Costa, 2003), que buscam descrever ações com famílias, visando intervir em seu sofrimento, e que são complementares em seus paradigmas clínicos com expressão no ambiente sócio-comunitário. Entendemos que o sistema familiar propicia o âmbito dessa experiência porque oferece conflitos de natureza pessoal (a baixa auto-estima da mãe, por exemplo), conflitos de natureza relacional (violência na interação conjugal), bem como conflitos entre os membros da família que estão vinculados à geração de renda local (adolescentes ingressando no narcotráfico).

Guareschi (2004) aponta como primordial a reflexão sobre o conceito de relação, colocando-o como "o conceito central" da Psicologia Social (p. 60), e enfatizando que estamos em relação, e que o grupo é a existência ou não de relações. Esse mesmo ponto focal é também a proposta epistemológica de Vasconcellos (2002). Essa autora, uma psicóloga com grande produção nacional e reconhecimento internacional, tem inspirado a discussão, no contexto dos terapeutas familiares, sobre o que se trata uma abordagem relacional. Sua proposta compreende uma perspectiva sistêmica que se configura numa visão do sujeito na relação com o outro, na sua condição inerente de complexidade, no reconhecimento da presença da subjetividade/individualidade nas relações. Essa perspectiva é de contextualização, a partir de causalidades recursivas, da instabilidade dos sistemas e da inclusão do observador na observação e na construção do conhecimento.

Em uma perspectiva da Psicologia Sócio-histórica e da Psicologia Social Comunitária, as relações são analisadas na forma como se dão entre indivíduos e/ou entre indivíduos e instituições. A dimensão do poder tem relevância central na análise das relações. Elas podem ser configuradas como relações de dominação, quando há a assimetria de poder ou como relações comunitárias, que ocorre quando há igualdade de direitos e deveres (Guareschi, 2000).

São dois enfoques diferentes para pensar relação, porém complementares, que podem ser contemplados nas questões que emergem no contexto comunitário, possibilitando ampliar a compreensão dos fenômenos abordados, produzindo uma intervenção mais complexa que integre a dimensão individual e social.

\section{RELAÇ̃̃O INDIVÍDUO E SOCIEDADE:}

\section{SUA IMPLICAÇÃO PARA PENSAR O SOFRIMENTO}

Uma intervenção comunitária, em alguma medida se dá quando há sofrimento, do indivíduo, de um grupo e/ou de uma comunidade. Intervir nesse sofrimento, sem pensar sobre os inúmeros elementos envolvidos em sua produção, pode ser, no mínimo, desastroso. 
Nesse sentido, pensamos necessário retomar a antiga discussão sobre a relação indivíduo-sociedade, não dicotomicamente, mas de uma maneira dialética, para se repensar a constituição do indivíduo. Vicent de Gaulejac (2001), um teórico da Sociologia Clínica, considera o homem como produto tanto dos determinantes psíquicos e sociais, não sendo estes equivalentes, porém dificilmente dissociáveis. Para esse autor, os determinantes sociais produzem um efeito psicológico que não pode ser compreendido apenas na sua dimensão individual, sob o "risco de aprisionarmos os indivíduos na impotência e culpabilidade" (p.39). Como também não podemos deixar de ver como as questões sociais e econômicas influenciam a forma como os indivíduos se organizam em sociedade.

Sawaia (2001) considera o sofrimento humano como ético-político, produzido por uma história de desigualdades e injustiças sociais, vivenciado pelo indivíduo, mas que tem origem nas relações intersubjetivas constituídas socialmente. Essa visão contribui para uma releitura do sofrimento, não como característico do indivíduo, mas como produto de processo histórico político, social e econômico de exclusão.

Nesse aspecto, a visão de homem sócio-histórico, apresentada por autores da Psicologia Social Comunitária e da Psicologia Sócio-Histórica se faz necessária nesse diálogo entre a clínica e a comunidade. A Psicologia como ciência, e da mesma forma a Psicologia Clínica, em sua busca de reconhecimento científico, construiu uma noção de fenômeno psicológico como algo interno ao homem. Bock (2002), ao criticar essa compreensão, aponta para a necessidade de compreender o fenômeno psicológico "como subjetividade, concebida como algo que se constitui na relação com o mundo material e social, mundo que só existe pela atividade humana" (p.23). Essa perspectiva crítica da Psicologia Social apresenta também uma crítica à própria história da Psicologia, que muitas vezes sustentou (e ainda sustenta) uma ideologia dominante e práticas excludentes, ao naturalizar o normal, negando sua naturalização histórica, e ao culpabilizar o indivíduo pelo seu próprio sofrimento (Bock, 2002).

É preciso cuidado para que não sigamos ajudando as pessoas a conviverem mais felizes em suas condições perversas de vida, naturalizando-as. É normal que a mulher cuide dos filhos, mas isso não faz parte da sua natureza. É normal ter poucos negros nas universidades, mas não é porque eles não sejam capazes de ingressar em um curso superior. A naturalização no indivíduo de fenômenos sociais deve ser denunciada em nossas práticas. Nós, profissionais da psicologia, e de outras áreas, que lidamos com o ser humano, precisamos assumir nossa responsabilidade nos processos de exclusão e estar atentos para não continuar estigmatizando e excluindo (Camino \& Ismael, 2003). Para isso, precisamos continuamente de uma prática reflexiva que questione a nós mesmos e a nossa visão de mundo para que nossas ideologias estejam evidenciadas.

Essa reflexão também tem estado presente entre expoentes da Terapia Familiar, ao criticarem a atuação, principalmente com famílias pobres e/ou de culturas distintas do grupo dominante, que possibilitava muito mais um ajuste à condição de pobreza, do que uma mudança efetiva da realidade (Pakman, 1998, 2003). Isso também é exemplificado pelo método da Just Therapy, desenvolvido por um grupo da Nova Zelândia (Waldegrave, 2001; Waldegrave \& Tamasese, 2001).

Wiesenfeld (1998) propõe que os conceitos e paradigmas utilizados na Psicologia Comunitária estejam em constante diálogo para a produção do conhecimento. Aponta ainda que o enfoque do trabalho comunitário seja visto como uma epistemologia, desse modo influenciando outras práticas referentes a outros contextos, como por exemplo, o clínico.

\section{CONSTRUINDO UMA DEMANDA}

Em nossa prática procuramos desenvolver uma circunstância de intervenção que tenha respaldo numa perspectiva sistêmica, como é debatido por Vasconcellos (2002) em sua discussão por compreender o enfoque sistêmico como sendo principalmente contextual. Procuramos ainda desenvolver uma ação que ofereça saídas para o principal impasse da intervenção comunitária, que é a falta de demanda. Não entendemos falta de demanda como falta de pedido de ajuda. Demanda, no sentido descrito na literatura (Neuburger, 1984), refere-se a um pedido de ajuda formulado, a um sofrimento declarado e a uma sintomatologia definida. Na visão da Psicossociologia, toda demanda é, ao mesmo tempo, uma demanda de objeto, endereçada a um outro compreendido como capaz de supri-la, o que torna inerente a isso uma relação de poder e dominação; e uma dimensão não explícita, do plano da psicologia, que expressa um desejo, uma falta mais difícil de ser percebida, chamada de demanda de amor (Lévy, 1994).

Na comunidade, em geral, são expressas as demandas de objeto às instituições que ali atuam, que atendem a essa finalidade. No entanto, não há escuta do que está por trás dessa demanda concreta, e por isso, a demanda de amor, quase nunca é ouvida, sendo freqüentemente reformulada em uma outra demanda de objeto. O sofrimento que acompanha tais pedidos não tem a quem ser endereçado, o sofrimento é o lugar comum e, assim, porque declará-los? E os sin- 
tomas não se constituem em problemas. Em nossa experiência, essa demanda necessita ser vista e escutada de outra forma. Todas as vezes que pudemos oferecer tempo, diálogo rico, disponibilidade para relação, a demanda de amor surgiu.

Refletir sobre a natureza da demanda faz-se necessário quando nos deparamos com uma compreensão generalizada no senso comum, e, alarmantemente, no meio acadêmico, de que as pessoas de baixa renda não têm sofrimento psíquico, mas necessidade de "encher a barriga". Nada mais ingênuo e insultuoso. Sem negarmos questões concretas de sobrevivência, consideramos errado e incompetente oferecer a essa população modos de ação que estejam ligados a valores e regras de convivência de outras classes sócio-econômicas, negando a elas o que "supomos" não ser uma necessidade básica. Essa questão tem sido abordada por diferentes teóricos, como podemos exemplificar com a contribuição de Marcelo Pakman, que discute que o atendimento a famílias e pacientes situados em uma fronteira cultural e socioeconômica diferente da nossa, requer uma reflexão constante do trabalho realizado, bem como uma terapia da terapia, para se evitar práticas alienadas e alienantes (Pakman, 1993, 1998, 1999, 2003a). Da mesma forma, Pedro Demo (1991) insiste em denunciar que constantemente é dado ao pobre o que é pobre.

Nossa proposta de atendimento clínico comunitário busca situar-se em uma zona de intersecção da Psicologia Clínica com a Psicologia Social Comunitária, busca superar as diversas críticas já realizadas sobre trabalhos clínicos em comunidade, que não apresentavam uma reflexão teórica, metodológica, nem epistemológica, sendo apenas a transposição de modelos de consultório, para o contexto comunitário (Freitas, 1998, 2000).

Apoiadas nos pressupostos epistemológicos acima explicitados, nós apresentamos, a seguir, alguns elementos fundamentais para o trabalho comunitário a partir de uma abordagem clínica.

\section{a) Enfoque nas relações}

Conforme apontado, anteriormente, a comunidade é definida por teóricos da Psicologia Social Comunitária a partir do conceito de relação. Consideramos fundamental que a intervenção comunitária nessa perspectiva clínica seja focada nas relações familiares, comunitárias, institucionais. Alguns trabalhos mostram a possibilidade de intervir junto a famílias de baixa renda, a partir do resgate da auto-estima e das competências, contribuindo também com a mobilização das redes sociais (Dabas, 1995).

O trabalho com Grupos Multifamiliares se apresenta como um instrumento que alcança tais objeti- vos, bem como demonstra eficácia no alívio de tensões, compartilhamento de sentimentos e ampliação da consciência sobre os problemas enfrentados e busca de soluções (Costa 1998, 1998a). Complementar a essa proposta mais educativa e preventiva dos Grupos Multifamiliares, Brandão (2001) investigou a tão praticada - mas pouco estudada - Visita Domiciliar como estratégia de intervenção com famílias de baixa renda. Esse instrumento mostrou-se adequado para aprofundar intervenções de questões que não são possíveis em grupo; vincular a família à instituição pela qual a visita acontece e mobilizar as redes sociais, pois o espaço da casa em famílias de periferia não tem o aspecto privado das famílias de classe média alta. A presença constante de vizinhos indica, não apenas que eles também compartilham daquela realidade, como também expressam uma rede de apoio da família (Brandão, 2001; Brandão \& Costa, 2003).

A intervenção a partir desse enfoque tem sido possibilitada por meio de técnicas desenvolvidas por terapeutas familiares, como a circularização e a devolução. A circularização é uma técnica que visa mobilizar fala de todos os presentes (Anderson \& Goolishian, 1993; Boscolo, Cecchin, Hoffman \& Penn, 1993) e a devolução, utilizada nas visitas, é uma carta que os visitadores escrevem para a família sobre o tema conversado, com o objetivo de mostrar novas formas de pensar sobre ele, provocar a família e ampliar a compreensão sobre o problema discutido (Ausloos, 1996; Molina-Loza, 2000; 2000a; Neubern et al., 2000).

Em ambas as estratégias de intervenção, o enfoque na mobilização das redes sociais constitui preocupação central, a fim de que possam ser incluídos, na resolução das questões que emergem, outros indivíduos e instituições da comunidade.

\section{b) Mobilização da rede social}

Rede social é um conceito que enfoca a interação humana e trata da mobilização da rede natural de contatos para o desenvolvimento e mudanças tanto individuais como familiares, e para a resolução de crises na família e na comunidade. Esse conceito surgiu em função da crise de identidade da sociedade atual, com a ruptura das redes sociais de pertencimento e de segurança. Uma revisão dos processos sociais, antropológicos e econômicos nos tem mostrado um processo de migração forte levando a desfiliação (Castel, 1994), isto é, quando os laços de pertencimento vão se debilitando.

Pensar "em rede" significa abandonar um paradigma de perceber a clientela como um alvo único da intervenção, e o profissional o único recurso possível. Significa repensar a relação que se estabelece entre as pessoas, as famílias, os adolescentes e os 
profissionais que com estas pessoas trabalham. Não mais uma relação desigual de reconhecimento de competências, mas um crédito na capacidade reflexiva e gerenciadora das pessoas de criarem e gerirem seus projetos de vida. Participar da construção de rede social é, antes de tudo, acreditar na rede de solidariedade entre pessoas e no potencial que elas possuem para compartilhar os problemas e as soluções em comum. Tentar conceituar rede social nos leva, antes, a assumir uma epistemologia (Saidón, 1995).

Para isto, precisamos retomar alguns pensamentos básicos sobre aportes teóricos atuais que trazem grandes contribuições para as ciências humanas. Um primeiro aspecto a ser pensado é o ser humano enquanto uma unidade biopsicosociocultural. Este enfoque traz em si a idéia de não dissociar da pessoa sua impregnação cultural, seu comportamento social e sua capacidade de se adaptar ao meio. O ser humano é resultado de sua história de relações com outras pessoas, com a família, com os grupos sociais e com a cultura.

Maturana (1998) enfoca o ser humano como um ser autopoiético, isto é, possuidor de uma organização de produção de componentes que em suas interações, constitui a rede de produções que o produz. O organismo se autoproduz. E continua: "Nós, seres vivos, somos sistemas determinados em nossa estrutura" (p.27). Somos determinados estruturalmente, mas não pré-determinados. Temos uma estrutura plástica que muda, em contato com o meio. Somos organizados de tal forma que, quando algo ocorre conosco, nossa reação depende de nós, depende desta nossa estrutura, e não daquele algo externo.

Um outro aspecto é a perspectiva de ordem/ desordem trazida por Morin (1995). A perspectiva de ordem, determinismo, linearidade, reducionismo é substituída por circularidade, desordem, complexidade, acaso, emergência do novo. É a partir desta compreensão de que a desordem é aparente e contém em si uma organização, que se expressa no ciclo do desenvolvimento. Isto implica perceber a unidade na diversidade e a diversidade na unidade.

Pakman (1992) traz uma concepção de que a auto-organização vem acompanhada de uma desorganização no sistema circundante. Existe uma regulação permanente do contato destas duas forças: auto-organização e desorganização. Sendo assim, entendemos que os organismos, os sistemas sociais se constituem em sistemas auto-organizadores, que produzem mudanças através da instalação e reinstalação de ordem e desordem sucessivamente.

"Pensar em rede", como diz Osvaldo Saidón (1995), constitui-se mais num plano de consistência do que numa organização, é mais um plano de imanência, do que de transcendência. Por isto "pen- sar em rede" traz um caminho teórico e, às vezes, prático; em outros momentos é uma estratégia e também uma organização, é uma epistemologia e um instrumental. Não há especialista em rede, a não ser aquele que encontra um modo de fazê-la funcionar.

A rede faz sentido na medida em que entra em nossa prática, não só como pensamento, mas também como promoção de acontecimentos que levem à participação e à solidariedade. Está implícito à formação de rede um resgate do ser como protagonista de sua vida e de suas relações sociais, uma transformação de pessoa-objeto em pessoa-sujeito, uma clara visualização de seus recursos emocionais e mentais, uma valorização de seus saberes, uma consciência de seu papel social. E isto diz respeito ao profissional que trabalha na facilitação desta construção, como para a clientela que participa do seu enriquecimento.

\section{c) Vinculação com instituições e líderes da comunidade}

É característico da intervenção psicossocial o vínculo com alguma instituição da comunidade. A instituição é, normalmente, o espaço no qual as relações comunitárias se estabelecem, sendo, assim, o contexto no qual os indivíduos apresentam suas demandas, explícitas ou implícitas. Rochael Nasciutti (2000) define, a partir da contribuição da psicossociologia, instituição como "tudo aquilo que se tornou instituído, reconhecido como tendo existência materializada na vida social" (p.103). Instituições são estabelecidas a partir da dinâmica social, e, dessa forma, é fundamental que a atuação comunitária seja por meio destas.

As demandas que chegam à psicologia, de forma geral, são originárias de alguma instituição. Postos de saúde, escolas, centros de assistência social; bem como instituições constituídas a partir de organização social, como Associação de Moradores, ONGs, ou instituições de natureza religiosa, são as portadoras iniciais dos pedidos da comunidade. Parte desse pedido inicial a busca de compreender as demandas, nem sempre claras, que existem na comunidade. $\mathrm{O}$ profissional deve partir dessas questões, escutar o que se fala na instituição, considerando que ela é uma das instituições na qual se apresenta a demanda. Quais outras dimensões do pedido existem? O que faz com que aquele pedido se expresse daquela forma naquela instituição? Qual a relação entre os integrantes da comunidade com a instituição que veicula o pedido? Qual a história da instituição naquela comunidade?

Essas questões são importantes para evitar a ingenuidade de pensar que uma instituição representa todos os integrantes da comunidade, ou de acreditar na eficácia de uma intervenção que não se concretize via instituição. A instituição é, pois, mediadora 
entre a comunidade e o profissional. O trabalho deste ocorre nesse ponto de tensão: estar submetido às regras, ao funcionamento e à dinâmica da instituição, sem sucumbir ao instituído.

Ainda nesse aspecto, a relação com instituições em comunidades de baixa renda apresenta um desafio específico: o de não atender ao caráter assistencialista que historicamente caracteriza as entidades que atuam nesse contexto.

\section{d ) Ação que vise autonomia e autogestão}

$\mathrm{O}$ assistencialismo não caracteriza apenas a doação de produtos concretos. Há os assistencialismos afetivo e emocional que também sustentam relações de dominação (Guareschi, 2000). Essa forma de relação inviabiliza a emergência do sujeito como ator social, a potencialização das suas próprias capacidades de refletir sobre social e de transformar sua realidade. Minuchin e colaboradores (1999) analisam que as famílias pobres não estão acostumadas a exercer um papel ativo na resolução de seus problemas. Isso porque as ações das instituições sociais muitas vezes assumem as decisões em busca de proteger quem possa parecer mais frágil e/ou ameaçado, deixando de ver o sistema de forma mais ampla. Os autores apontam ser necessário que a equipe tenha habilidades para estimular uma postura mais ativa da família, paradoxalmente, aprendendo a "trabalhar muito ao assumir um papel menos importante" (Minuchin e cols., 1999, p.46).

A intervenção comunitária deve viabilizar que os próprios membros da comunidade desenvolvam mecanismos de ajuda, não permanecendo dependentes da intervenção efetuada. Parafraseando Pedro Demo (1991), intervenção bem feita é aquela que se torna dispensável. Para isso, o trabalho realizado deve ser uma negociação entre profissional e comunidade, bem como deve ser constantemente avaliado pela comunidade, estando a cargo da mesma, a definição da continuidade ou não.

Sem esgotar as possibilidades de reflexão sobre as contribuições teóricas da abordagem clínica em contexto comunitário e com muito ainda a ser construído em termos metodológicos, adequados as particularidades de cada contexto, apresentamos nesse trabalho a forma como temos produzido a nossa prática, a fim de contribuir para esse contínuo processo.

Nessa proposta, o trabalho com grupos comunitários deve considerar não apenas a questão da saúde mental, como tradicionalmente tem sido enfocado (Celia, 1997), mas incluir a dimensão sócio-histórica, as relações de poder como passíveis de produzir sofrimento psíquico, devendo ser abordadas de forma mais ampla. Esse diálogo proposto nesse texto visa contribuir para uma intervenção que repense paradigmas e metodologias de forma a adequá-los à realidade social e econômica brasileira.

\section{REFERÊNCIAS}

Anderson H. \& Goolishian, H. (1993). O Cliente é o Especialista. Uma abordagem para terapia a partir de uma posição de Não Saber. Nova Perspectiva Sistêmica, Rio de Janeiro, ano II, n. 3: 8-23.

Ausloos, G. (1996). A Competência das Famílias. Tempo, caos e processo. Lisboa: CLIMEPSI.

Barbier, R. (1985). Pesquisa ação na instituição educativa. Rio de Janeiro: Jorge Zahar.

Bock, A.M.B. (2002). A Psicologia Sócio-Histórica: uma perspectiva crítica em psicologia. In: A.M.B. Bock; M.G.M. Gonçalves \& O. Furtado (Orgs.). Psicologia Sócio-Histórica (pp.15-35). Uma perspectiva crítica em Psicologia. São Paulo: Cortez. $2^{\mathrm{a}}$ Ed..

Boscolo, L.; Cecchin, G.; Hoffman, L. \& Penn, P. (2003). A Terapia Familiar Sistêmica de Milão. Conversações sobre teoria e prática. Porto Alegre: Artes Médicas.

Brandão, S. N. \& Costa, L. F. (2004). Visita Domiciliar como Proposta de Intervenção Comunitária. In: M. A. Ribeiro \& L. F. Costa. Família e Problemas na Contemporaneidade: Reflexões e Intervenções do Grupo Socius (pp. 157-179).Brasília: Universa.

Brandão, S.N. (2001). Visita Domiciliar: ampliando intervenções clínicas em comunidade de baixa renda. Dissertação de Mestrado, Universidade de Brasília, Brasília-DF.

Camino, L. \& Ismael, E. (2003). O papel da psicologia nos processos de exclusão. In: A.M.C. Guerra; L. Kind; L. Afonso; M.A.M. Prado (Orgs.). Psicologia Social e Direitos Humanos (pp.185-200). Belo Horizonte: Edições Campo Social.

Carone, I. (2003). A Psicologia tem paradigmas? São Paulo: Casa do Psicólogo/FAPESP.

Castel, R. (1994). Da indigência à exclusão, a desfiliação. Precariedade do trabalho e vulnerabilidade relacional. In: Lancetti, A. (Org.). Saúde Loucura, n.4, (pp. 21-48). São Paulo: Hucitec.

Celia, S. (1997). Grupos Comunitários. In: Zimmerman, D.E \& Osorio, L.C. Como trabalhamos com grupos (pp.101-105). Porto Alegre: Artes Médicas. 
Conselho Federal de Psicologia. (Acesso em 05 abr. 2005.) Código de Ética do Profissional Psicólogo, 1987. Disponível em: < http://www.pol.org.br/legislacao/ pdf/codigo_de_etica.pdf $>$.

Costa, L. F. (2003). E Quando Termina em Mal Me Quer? Reflexões acerca do Grupo Multifamiliar e da Visita Domiciliar como Instrumentos da Psicologia Clínica na Comunidade. Brasília: Universa.

Costa, L. F. (1999). O Trabalho da Psicologia Clínica na Comunidade através do Psicodrama: a Reunião Multifamiliar. Revista Brasileira de Psicodrama, São Paulo, v. 7, n. 2: $17-34$.

Costa, L. F. (1998/1999.). Possibilidade de criação de um contexto educativo: grupos multifamiliares. Linhas Críticas, Brasília, v. 4, n. 7-8: 159-174.

Costa, L.F. (1998a). Reuniões multifamiliares: condição de apoio, questionamento e reflexão no processo de exclusão de membros da família. Ser Social, Brasília, n. 3: 245-272.

Costa, L.F. (1998). Reuniões Multifamiliares: Uma Proposta de Intervenção em Psicologia Clínica na Comunidade. Tese de Doutorado, Universidade de São Paulo, São Paulo.

Dabas, E.N. (1995). A Intervenção em Rede. Nova Perspectiva Sistêmica, Rio de Janeiro n. 6, 3-18.

Demo, P. (1991). Assistência Social como direito da cidadania. Brasília: Apostila, DME/SAE.

Freitas, M.F.Q. (1998). Novas Práticas e Velhos Olhares em Psicologia Comunitária. In: Souza, L.; Freitas, M.F.Q \& Rodrigues, M.M.P. (Orgs.). Psicologia: reflexões (im)pertinentes (pp. 83-108). São Paulo: Casa do Psicólogo.

Freitas, M.F.Q. (2000). Psicologia na comunidade, psicologia da comunidade e psicologia (social) comunitária: Práticas da psicologia em comunidade nas décadas de 60 a 90, no Brasil. In: Campos, R.H.F. (Org.). Psicologia Social Comunitária - da solidariedade à autonomia. (pp.54-80). 4ª Ed. Petrópolis: Vozes.

Gaujelac, Vincent de. (2001). Psicossociologia e sociologia clínica. In Araújo, J. N. G. de e Carreteiro, T.C. (orgs). Cenários Sociais e abordagem clínica. (pp 3547). São Paulo: Escuta.

Guareschi, P. (2003). Ética e paradigmas. In: Ploner,
K.S;. Michels, L.R.F; Schlindwein, L.M. \& Guareschi, P.A. (Orgs.) Ética e Paradigmas na Psicologia Social. (p.17-33). Porto Alegre: ABRAPSOSUL.

Guareschi, P. (2000). Relações Comunitárias - Relações de Dominação. In: Campos, R.H.F. (Org.). Psicologia Social Comunitária - da solidariedade à autonomia. (pp.81-99). $4^{\mathrm{a}}$ Ed. Petrópolis: Vozes.

Guareschi, P. (2004). Psicologia Social Crítica como prática de libertação. Porto Alegre: EDIPUCRS.

Lévy, A. A. (1994). Psicossociologia: crise ou renovação? In: Mata Machado, M.N. et al (Orgs.) Psicossociologia. Análise social e intervenção (pp.101121). Petrópolis: Vozes.

Maturana, H. Emoções e Linguagem na Educação e na Política. Belo Horizonte: Editora UFMG, 1998.

Minuchin, P.; Colapinto, J. \& Minuchin, S. (1999). Trabalhando com Famílias Pobres. Porto Alegre: Artes Médicas.

Molina-Loza, C.A. (2000 a.). Eu não sabia... mas Clio me contou. Narrativas Terapêuticas II. Belo Horizonte: ArteSã.

Molina-Loza, C.A. (2000). Histórias, contadas com amor, para mudar e crescer. Narrativas Terapêuticas I. Belo Horizonte: ArteSã.

Morin, E. Introdução ao Pensamento Complexo. Lisboa: Instituto Piaget, $2^{\text {a }}$ Ed., 1995.

Neubern, M.; Egg, R.; Guimarães, I.; Mazali, L. \& Pereira, M.H. (2000). Texto não publicado, Devoluções Escritas em Terapia Familiar: Um Estudo Inicial.

Neuburger, R. (1994). Psychanalyse et thérapie familiale systhémique. Paris: ESF.

Pakman, M. (2003a). Conhecimento disciplinar, posmodernismo e globalização: uma chamada à "virada reflexiva" de Donald Schön para as profissões de saúde mental. Nova Perspectiva Sistêmica, ano XII, n. $22: 7-45$.

Pakman, M. (1999). Desenhando Terapias em Saúde Mental Comunitária: Poética e Micropolítica Dentro e Além do Consultório. Nova Perspectiva Sistêmica, Rio de Janeiro, ano VIII, n. 13: 6-25.

Pakman, M. (1998). Educação e Terapia em Fronteiras Culturais: Por Práticas Sociais Críticas nos Serviços 
Pakman, M. (2003). Elementos para una poética foersteriana en la práctica psicoterapéutica. Sistema Familiares y otros Sistemas, Buenos Aires, v. 19, n. $3: 49-64$.

Pakman, M. (1993). Terapia Familiar em contextos de Pobreza, Violência e Dissonância Étnica. Nova Perspectiva Sistêmica, Rio de Janeiro, n. 4: 8-19.

Ricci, L. (2003) Psicologia Comunitária Transformativa. In:. Guerra, A.M.C et al (Orgs.) Psicologia Social e Direitos Humanos (pp.227-243). Belo Horizonte: Edições Campo Social.

Rochael Nasciutti, J. (2000). A instituição como via de acesso à comunidade. In: Campos, R.H.F. (Org.). Psicologia Social Comunitária - da solidariedade à autonomia (pp.100-126), 4ªEd. Petrópolis: Vozes.

Saffioti, H. I. B. (1992). Rearticulando gênero e classe social. In: Costa, A.O. \& Bruschini, C. (Orgs.) Uma questão de gênero. São Paulo: Rosa dos Tempos/Fundação Carlos Chagas.

Saidón, O. (1995). Las redes: pensar de otro modo. In: DABAS, E. \& Najmanovich, D. (Orgs.) Redes. El lenguaje de los vínculos. Hacia la reconstrucción y el fortalecimiento de la sociedad civil (pp. 203-207). Buenos Aires: Paidós

Sawaia, B. (2000). Comunidade: a apropriação científica de um conceito tão antigo quanto a humanidade. In: Campos, R.H.F. (Org.). Psicologia Social Comunitária - da solidariedade à autonomia (pp.35-53). $4^{\mathrm{a} E d}$. Petrópolis: Vozes.

Sévigny, Robert. (2001). Abordagem clínica nas ciências humanas. In Araújo, J. N. G. de \& Carreteiro, T.C. (orgs), Cenários Sociais e abordagem clínica (pp 12-33). São Paulo: Escuta.

Vasconcellos, M. J. E. (2002). Pensamento sistêmico. O novo paradigma da ciência. São Paulo: Papirus.

Waldegrave, C. \& Tamasese, K. (2001). Algumas idéias centrais no método da Just Therapy. Nova Perspectiva Sistêmica ${ }_{2}$ Rio de Janeiro, Ano X, n. 19: 9-25.

Waldegrave, C. (2001a). "Just Therapy" com famílias e comunidades. In: M.A. Grandesso (Org.) Terapia e Justiça Social: respostas éticas a questões de dor em terapia. (pp.19-35). São Paulo: APTF
Wiesenfeld, E. (1998). El construccionismo crítico: su pertinencia en la psicologia social comunitaria. Psicologia e Sociedade, São Paulo, v. 10, n. 2: 137-157.

Liana Fortunato Costa é Psicóloga, Terapeuta Familiar, Psicodramatista, Doutora em Psicologia Clínica pela Universidade de São Paulo, Pesquisadora Associada Adjunto da Universidade de Brasília, afiliada ao Departamento de Psicologia Clínica e desenvolve suas pesquisas no Laboratório de Família, Grupos e

Comunidade. O endereço para correspondência é:

Instituto de Psicologia. Universidade de Brasília, Caixa Postal 4500 *70.910-900 Brasília, DF, Brasil.

E-mail: lianaf@zaz.com.b

Shyrlene Nunes Brandão é Psicóloga, Mestre em Psicologia Clínica pela Universidade de Brasília, Formação em Psicodrama no Centro de Psicodrama de Brasília - CEPB. O endereço postal da autora é: Universidade Católica de Brasília, Curso de Psicologia. Campus 1. Q.S. 07. Lote 01. CEP: 71966700. Águas Claras, Taguatinga.E-mail: shyrlene@ucb.br

\section{Liana Fortunato Costa \\ Shyrlene Nunes Brandão \\ Abordagem clínica no contexto comunitário: uma perspectiva integradora \\ Recebido: 16/11/2004 \\ $1^{\text {a }}$ revisão: 23/05/2005 \\ Aceite final: 21/07/2005}

